\title{
The Relationship between Nanocluster Precipitation and Thermal Conductivity in Si/Ge Amorphous Multilayer Films: Effects of Cu Addition
}

\author{
Ahmad Ehsan Mohd Tamidi ${ }^{1}$ and Yasushi Sasajima ${ }^{2,3}$ \\ ${ }^{1}$ Graduate School of Science and Engineering, Ibaraki University, 4-12-1 Nakanarusawa, Hitachi 316-8511, Japan \\ ${ }^{2}$ Department of Materials Science and Engineering, Faculty of Engineering, Ibaraki University, 4-12-1 Nakanarusawa, \\ Hitachi 316-8511, Japan \\ ${ }^{3}$ Frontier Research Center for Applied Atomic Sciences, Ibaraki University, Shirakata 162-4, Tokai 319-1106, Japan \\ Correspondence should be addressed to Yasushi Sasajima; yasushi.sasajima.mat@vc.ibaraki.ac.jp
}

Received 13 November 2015; Accepted 3 March 2016

Academic Editor: Magnus Willander

Copyright (C) 2016 A. E. Mohd Tamidi and Y. Sasajima. This is an open access article distributed under the Creative Commons Attribution License, which permits unrestricted use, distribution, and reproduction in any medium, provided the original work is properly cited.

\begin{abstract}
We have used a molecular dynamics technique to simulate the relationship between nanocluster precipitation and thermal conductivity in $\mathrm{Si} / \mathrm{Ge}$ amorphous multilayer films, with and without $\mathrm{Cu}$ addition. In the study, the Green-Kubo equation was used to calculate thermal conductivity in these materials. Five specimens were prepared: $\mathrm{Si} / \mathrm{Ge}$ layers, $\mathrm{Si} /(\mathrm{Ge}+\mathrm{Cu})$ layers, $(\mathrm{Si}+$ $\mathrm{Cu}) /(\mathrm{Ge}+\mathrm{Cu}$ ) layers, $\mathrm{Si} / \mathrm{Cu} / \mathrm{Ge} / \mathrm{Cu}$ layers, and $\mathrm{Si} / \mathrm{Cu} / \mathrm{Ge}$ layers. The number of precipitated nanoclusters in these specimens, which is defined as the number of four-coordinate atoms, was counted along the lateral direction of the specimens. The observed results of precipitate formation were considered in relation to the thermal conductivity results. Enhancement of precipitation of nanoclusters by $\mathrm{Cu}$ addition, that is, densification of four-coordinate atoms, can prevent the increment of thermal conductivity. Cu dopant increases the thermal conductivity of these materials. Combining these two points, we concluded that $\mathrm{Si} / \mathrm{Cu} / \mathrm{Ge}$ is the best structure to improve the conversion efficiency of the $\mathrm{Si} / \mathrm{Ge}$ amorphous multilayer films.
\end{abstract}

\section{Introduction}

Electricity is an important type of energy. It can be generated from other primary sources, for example, steam, oil, coal, wind, sunlight, and nuclear reactions. However, sources like coal and oil are not good for the environment as they emit much carbon dioxide when burned, and they also will be depleted in the future. Other sources like wind and sunlight do not produce much energy on a steady basis. These problems have led to the consideration and use of renewable and sustainable energy sources.

People in Japan have become more interested in renewable and sustainable energy techniques after their experiences in the summer months following the massive earthquake and tsunami that struck northeastern Japan in March 2011 and led to the Fukushima nuclear accident, when the government implemented various energy saving measures to compensate for the loss of nuclear power-generated electricity. These techniques should be environmentally conscious. Using thermoelectric materials is one energy saving technique. Approximately $90 \%$ of the world's electricity is generated by heat energy, typically operating at $30 \%-40 \%$ efficiency, thus losing massive amounts of energy in the form of heat released to the environment [1]. Therefore, extracting energy from waste heat by using thermoelectric materials is a promising approach.

Thermoelectric materials are materials that can transfer heat into energy [2-4]. These materials produce electricity from heat using the Seebeck effect. This is a phenomenon that uses a temperature difference between two dissimilar electrical conductors or semiconductors to produce a voltage 
difference between two substances $[5,6]$. Efficiency of these materials depends on the figure of merit ZT:

$$
\mathrm{ZT}=\frac{\alpha^{2}}{\rho \kappa} T,
$$

where $T, \alpha, \rho$, and $\kappa$ are the absolute temperature, Seebeck coefficient, electrical resistivity, and thermal conductivity, respectively. Silicon-germanium alloys are currently the best thermoelectric materials around $1000 \mathrm{~K}$. Usability of SiGe alloys is, however, limited by their high price and their ZT is also only in the midrange.

High thermoelectric power (Seebeck coefficient) has been found when recrystallization of nanocrystals occurs in a thin film. Nanocrystals that formed in the thin films are believed to be the effect of the metal-induced crystallization (MIC) of the dopant metals. MIC is a phenomenon whereby dopant metal atoms lower the recrystallization temperature of an amorphous semiconductor [7]. This suggests that superior thermoelectric properties will arise from the nanocrystals in the amorphous matrix $[8,9]$.

Unfortunately, in the experiment conducted by Takiguchi et al. [8], when they attempted to make $\mathrm{Si} /(\mathrm{Ge}+\mathrm{B})$ superlattice thin film, there was no sign of the MIC effect. In fact, high thermoelectric power $\left(>1 \mathrm{mVK}^{-1}\right)$ was observed in the superlattice thin film only when nanocrystals with a diameter less than $10 \mathrm{~nm}$ were present; however, limitations of the specimen preparation system and the use of $B$ as the dopant made it difficult to prepare specimens with a precisely controlled nanostructure.

In our previous work [10], four specimens were studied by a molecular dynamics (MD) simulation technique. Specimens with $\mathrm{Cu}$ addition to the $\mathrm{Si}$ or Ge layer showed a low number of nanoclusters that were defined by the number of four-coordinate atoms. However, if a thin $\mathrm{Cu}$ layer was present at the interfaces of $\mathrm{Si}$ and $\mathrm{Ge}$, it enhanced the precipitation of the four-coordinate atoms. Thus we proposed that by controlling the $\mathrm{Cu}$ impurity addition and the way $\mathrm{Cu}$ was placed in the system we could control the precipitation of nanoclusters and improve the thermoelectric performance.

In this paper, we report further understanding on the relationship between the nanocluster precipitations and the thermal conductivity of the $\mathrm{Si} / \mathrm{Ge}$ amorphous multilayer films with $\mathrm{Cu}$ addition. The MD simulation technique was used to obtain a metastable structure of the specimens. The Green-Kubo equation was applied to calculate the thermal conductivity of the specimens. The simulation results for the precipitated nanoclusters, which are represented by fourcoordinate atoms, and the results of thermal conductivity were analyzed in this study.

\section{Simulation Technique}

2.1. Simulation Details. In this study, we used the MD simulation technique which calculates individual movements of atoms and molecules. The trajectories of atoms and molecules are determined by numerically solving Newton's equations of motion for a system of interacting particles, where forces between the particles and potential energy are defined by molecular mechanics force fields. This technique is also well suited to describe materials at the atomic scale $[9,11,12]$. In the MD technique, the position of the $i$ th atom, $\mathbf{R}_{i}$, is calculated by the Newton equation:

$$
\mathbf{f}_{i}=m \frac{d^{2} \mathbf{R}_{i}}{d t^{2}}
$$

where $\mathbf{f}_{i}$ is force acting on particle $i$ and $m$ is mass of the particle.

An extended Tersoff potential was used to calculate the interaction between atoms in this simulation. This is one member of the family of potentials developed by Tersoff [13], and based on the concept of bond order, the strength of a bond between two atoms is not constant but depends on the local environment. Moreover, this potential has been proven to be reliable, and it is widely used recently [14-16].

In the extended Tersoff potential, potential energy is calculated within the pair of atoms $i$ and $j$ which can be expressed in the following form:

$$
U_{T}=\sum_{i} \sum_{j} \frac{u_{i j}}{2}+\sum_{i} \phi_{i}
$$

which means that the potential acting on the whole system is the summation of interatomic potential of the two-body force and the potential of the charge inside the particles. To calculate $u_{i j}$ and $\phi_{i}$, we used the following expression:

$$
\begin{aligned}
u_{i j} & =u_{R i j}+u_{S i j}+u_{I i j}+u_{V i j}, \\
\phi_{i} & =\left[\frac{\left(I_{E i}+A_{E i}\right)}{2 e}\right] q_{i}+\left[\frac{\left(I_{E i}-A_{E i}\right)}{2 e^{2}}\right] q_{i}{ }^{2} .
\end{aligned}
$$

In this expression, $u_{R i j}, u_{S i j}, u_{I i j}$, and $u_{V i j}$ are repulsive force, attractive force, coulomb force, and Van der Waals' force, respectively. More information about the extended Tersoff potential may be found in the literature [17].

In this work we used the Green-Kubo equation to calculate the thermal conductivity. The Green-Kubo equation is one of several well-known approaches $[18,19]$ used to predict thermal conductivity in an equilibrium MD simulation. In the equilibrium MD simulation, the molecules are allowed to interact in the absence of any perturbing field (e.g., a temperature gradient). This equation also can be applied to crystals, alloys, amorphous solids, and fluids.

The Green-Kubo equation relates the equilibrium fluctuation of the heat current vector, $S$, to the thermal conductivity tensor via the fluctuation-dissipation theorem. The thermal conductivity in the direction $x$ is

$$
\lambda_{x}=\frac{V}{k_{B} T^{2}} \int_{0}^{\infty}\left\langle S(t)_{x} S(0)_{x}\right\rangle d t,
$$

where $k_{B}$ is the Boltzmann constant, $V$ is specimen volume, $T$ is specimen temperature, $t$ is time, and $S_{x}$ and $\left\langle S(t)_{x} S(0)_{x}\right\rangle$ are the $x$ components of the heat current vector and the heat current autocorrelation function. By using the extended Tersoff potential, we calculated the heat current vector having 
three components ( $x, y$, and $z$ directions). Therefore, (5) becomes

$$
\lambda=\frac{V}{3 k_{B} T^{2}} \int_{0}^{\infty}\langle\mathbf{S}(t) \cdot \mathbf{S}(0)\rangle d t
$$

and the $\mathbf{S}$ component formula is

$$
\mathbf{S}=\frac{1}{V}\left[\sum_{j} e_{j} \mathbf{v}_{j}+\frac{1}{2} \sum_{i \neq j} \mathbf{r}_{i j}\left(\mathbf{f}_{i j} \cdot \mathbf{v}_{j}\right)\right],
$$

where $e_{j}$ is the total energy of the $j$ th atom, subtracted by the average energy of atoms $\langle e\rangle$ as follows:

$$
e_{j}=\frac{1}{2} m v_{j}^{2}+\frac{1}{2} \sum_{i \neq j)} u_{i j}+\phi_{j}-\langle e\rangle .
$$

2.2. Specimen Details. In this work, we simulated five types of specimens: four of them were similar to those used in our previous paper [10] and they had multilayers of $\mathrm{Si} / \mathrm{Ge}, \mathrm{Si} /(\mathrm{Ge}+$ $\mathrm{Cu}),(\mathrm{Si}+\mathrm{Cu}) /(\mathrm{Ge}+\mathrm{Cu})$, and $\mathrm{Si} / \mathrm{Cu} / \mathrm{Ge} / \mathrm{Cu}$, and the fifth type had multilayers of $\mathrm{Si} / \mathrm{Cu} / \mathrm{Ge}$, which we thought was an important structure to consider. "+Cu” means that $\mathrm{Cu}$ atoms were added to the Si or Ge layers as substitutional atoms and "/" indicates the interface of the layers.

Specimen 1 contained only Si and Ge, described as Si/Ge. In Specimen 2, we added $\mathrm{Cu}$ to only the Ge layer at the ratio of $\mathrm{Ge}: \mathrm{Cu}=6: 4$, described as $\mathrm{Si} /(\mathrm{Ge}+\mathrm{Cu})$. In Specimen 3, we added 20 at \% $\mathrm{Cu}$ to both the $\mathrm{Si}$ and Ge layers, described as $(\mathrm{Si}+\mathrm{Cu}) /(\mathrm{Ge}+\mathrm{Cu})$. In Specimens 4 and 5 , we formed a thin $\mathrm{Cu}$ layer. The former had a thin $\mathrm{Cu}$ layer at both $\mathrm{Si}$ and $\mathrm{Ge}$ interfaces, described as $\mathrm{Si} / \mathrm{Cu} / \mathrm{Ge} / \mathrm{Cu}$. The latter had a thin $\mathrm{Cu}$ layer at only the $\mathrm{Si}$ interface, described as $\mathrm{Si} / \mathrm{Cu} / \mathrm{Ge}$.

All five specimens contained the same numbers and dimensions of the unit cell: ten cells $(5.54 \mathrm{~nm})$ in the $\langle 100\rangle$ and $\langle 010\rangle$ directions. For numbers and dimensions of the unit cell in the $\langle 001\rangle$ direction, Specimens 1, 2, and 3 contained the same numbers of unit cell, which was six unit cells $(3.33 \mathrm{~nm})$, Specimen 4 had eight unit cells $(4.43 \mathrm{~nm})$, and Specimen 5 had seven unit cells $(3.88 \mathrm{~nm})$. The lattice constant of the unit cell was set to be the average of the lattice constants of Si and Ge.

First, all five specimens were melted at a temperature $5000 \mathrm{~K}$. Then, we quenched them at $4.5 \mathrm{~K}$. After the multilayered films became amorphous, we tracked the location and velocity of every atom for the thermal conductivity calculation. The amorphous multilayered films were next annealed at $1000 \mathrm{~K}$. After annealing, we once again tracked the location and velocity of every atom for the thermal conductivity calculation. The Verlet algorithm was used for the calculation of atomic movement [20], while the discrete time $\Delta t$ was set as $0.3 \mathrm{fs}$. The bookkeeping and cell-index methods were used to reduce computing time. The periodic boundary conditions were applied to eliminate surface effect from the computation. Side views of the final structure of the five types of specimens from the [010] direction are shown in Figure 1.

\section{Results and Discussion}

3.1. Cluster Distribution. We analyzed the cluster distribution. To do this, first, a cluster was defined according to its number of coordination atoms, which was four. The number of four-coordinate atoms was counted in every specimen before and after annealing. Unlike in our previous work [10], we considered that the number of four-coordinate atoms must be calculated at the same stable temperature. Thus, the number of four-coordinate atoms was counted at $300 \mathrm{~K}$.

Figure 2 shows the total number of four-coordinate atoms before and after annealing for every specimen. From this, we can understand that, after annealing, all specimens show a greater number of four-coordinate atoms. Specimen 5 shows the highest enhancement, followed by Specimens 1, 4, 2, and 3.

After that, the distribution of the number of fourcoordinate atoms was analyzed along the lateral direction of the film, [010]. Along the sides in the [100] and [001] directions, every specimen was divided at $0.2 \mathrm{~nm}$ interval, to create cells with a size of $0.2 \mathrm{~nm} \times 5.5 \mathrm{~nm} \times 0.2 \mathrm{~nm}$. After that, the number of four-coordinate atoms present inside the cell was obtained. The analyzed results are shown in Figure 3. In this figure, the $x$-axis is the number of layers in the [100] direction of every specimen, while the $y$-axis is the number of layers in the [001] direction. The number of four-coordinate atoms is presented by the color contour which represents the density of four-coordinate atoms inside every cell.

For Specimen 1 (Figure 3(a)), when we compare the distribution of the number of four-coordinate atoms before and after annealing, they are uniformly found in the Si and Ge layers. When $\mathrm{Cu}$ dopant atoms were added to the Ge layer or both $\mathrm{Si}$ and Ge layers as in Specimens 2 and 3, small amount of the four-coordinate atoms was precipitated in the $\mathrm{Cu}$ region (the upper region of Figure 3(b) and the whole region of Figure 3(c)). We consider that this behavior might be due to the fact that the $\mathrm{Cu}$ had stabilized the structures of the $\mathrm{Si}$ and Ge layers in Specimens 2 and 3. Therefore, $\mathrm{Cu}$ had blocked the precipitation of four-coordinate atoms in the layer where it was doped.

However, in Specimen 2, the density of precipitation of four-coordinate atoms in the Si layer, that is, the $\mathrm{Cu}$-free layer, is higher compared to that of Specimen 1. Specimens 4 and 5 , in which a thin $\mathrm{Cu}$ layer was inserted between the $\mathrm{Si}$ and Ge layers, also show the same behavior as the Si layer in Specimen 2. Both Specimens 4 and 5 show enhancement of the number of the four-coordinate atoms in both $\mathrm{Si}$ and $\mathrm{Ge}$ layers. Moreover, Specimen 5 shows a greater enhancement of the total number of four-coordinate atoms than Specimen 1. Therefore, the $\mathrm{Cu}$ dopant and thin $\mathrm{Cu}$ layer can enhance precipitation and increase the density of four-coordinate atoms in the $\mathrm{Cu}$-free layers of $\mathrm{Si}$ and $\mathrm{Ge}$.

3.2. Thermal Conductivity. We calculated thermal conductivity using the Green-Kubo equation. For all specimens, thermal conductivity was calculated at $300 \mathrm{~K}$ for $3 \mathrm{fs}$. The thermal conductivity results are shown in Figure 4.

From Figure 4 we see that increasing the number of four-coordinate atoms does not always lower the thermal 


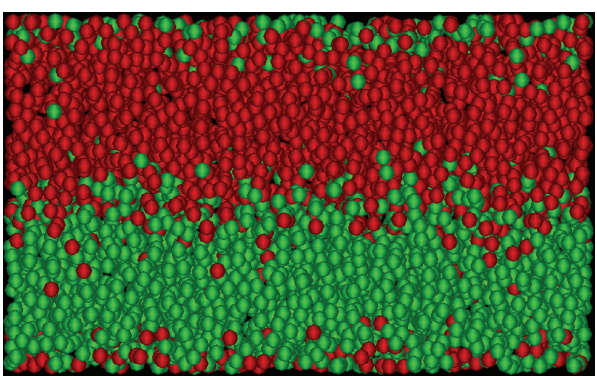

(a)

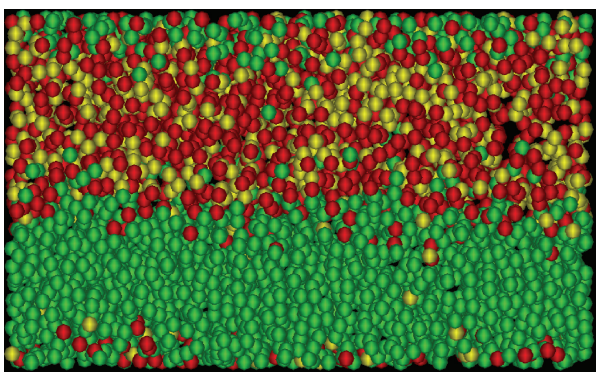

(b)

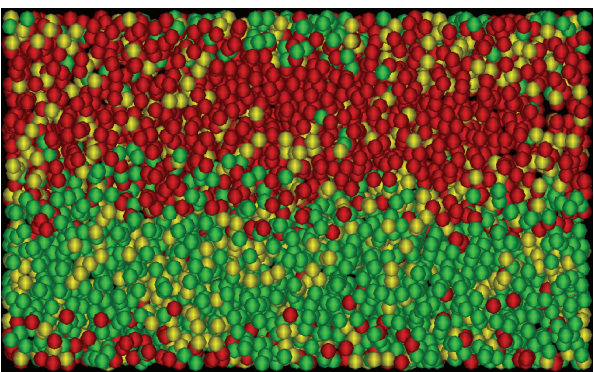

(c)

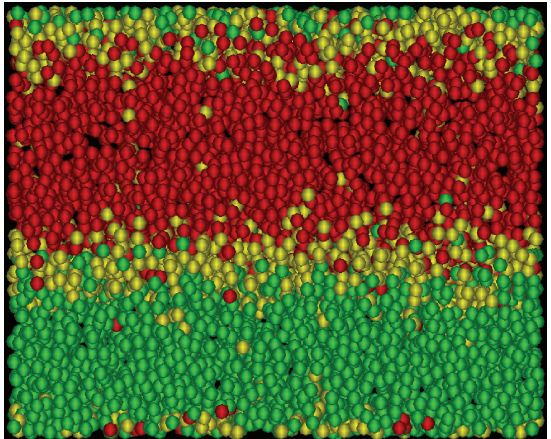

(d)

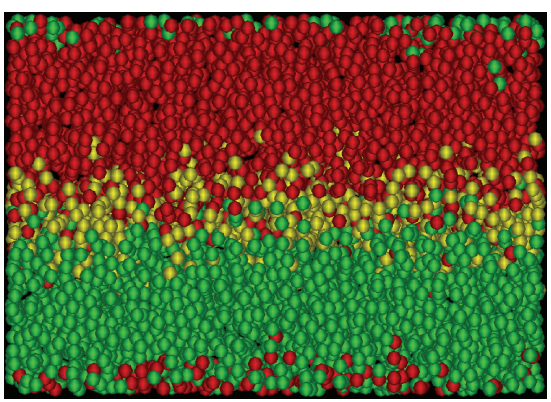

(e)

FIGURE 1: Side views of the final structure (after annealing process) of the five types of specimens from the [010] direction. (a) Specimen 1: $\mathrm{Si} / \mathrm{Ge}$, (b) Specimen 2: $\mathrm{Si} /(\mathrm{Ge}+\mathrm{Cu})$ with $\mathrm{Ge}: \mathrm{Cu}=6: 4$, (c) Specimen 3: $(\mathrm{Si}+\mathrm{Cu}) /(\mathrm{Ge}+\mathrm{Cu})$, with 20 at \% Cu in both layers, (d) Specimen 4: $\mathrm{Si} / \mathrm{Cu} / \mathrm{Ge} / \mathrm{Cu}$, and (e) Specimen 5: $\mathrm{Si} / \mathrm{Cu} / \mathrm{Ge}$. Green, red, and yellow particles represent $\mathrm{Si}, \mathrm{Ge}$, and $\mathrm{Cu}$ atoms, respectively.

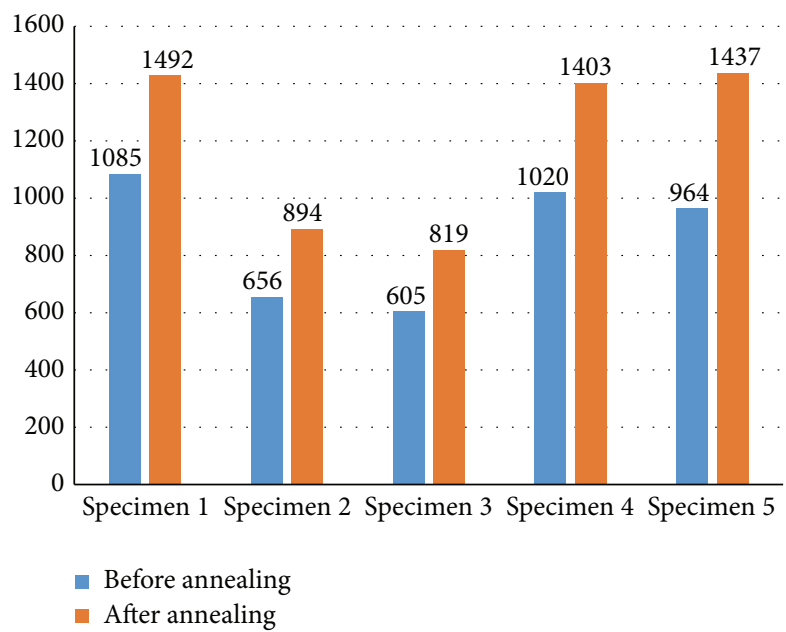

FIGURE 2: Total number of precipitated four-coordinate atoms in each specimen. conductivity. Specimens 1 and 5 show a reduction of thermal conductivity after annealing, while Specimens 2, 3, and 4 show an increment. We find that the density of $\mathrm{Cu}$ also plays a crucial role in thermal conductivity of these materials. The higher the $\mathrm{Cu}$ density, the higher the value of thermal conductivity. From this fact, we can consider that the $\mathrm{Cu}$ atoms can easily transmit atomic vibrations in Specimens 2, 3, 4, and 5. Comparing Specimens 2 and 3 for the amorphous state, Specimen 2 has a much higher thermal conductivity value than Specimen 3. This is due to the higher density of $\mathrm{Cu}$ in the Ge layer in Specimen 2 than in Specimen 3. In addition, if a $\mathrm{Cu}-\mathrm{Cu}$ bond is formed, this will also make the thermal conductivity value higher than for other bonds. This can be clearly seen when comparing Specimen 4 with Specimen 3 for the amorphous state. Thin $\mathrm{Cu}$ layers in Specimen 4 tend to transmit atomic vibrations much more easily than the $\mathrm{Si}$ and $\mathrm{Ge}$ layers with added $\mathrm{Cu}$ in Specimen 3. This makes the thermal conductivity of Specimen 4 greater than that of Specimen 3. 


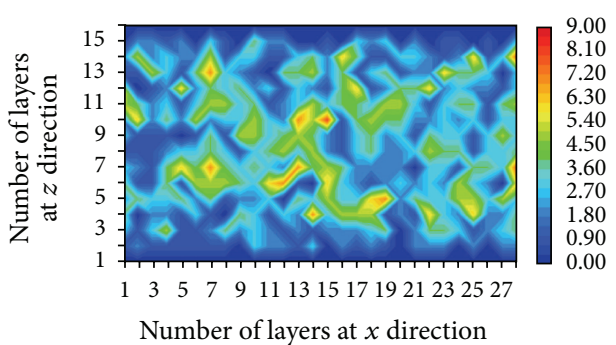

(1)

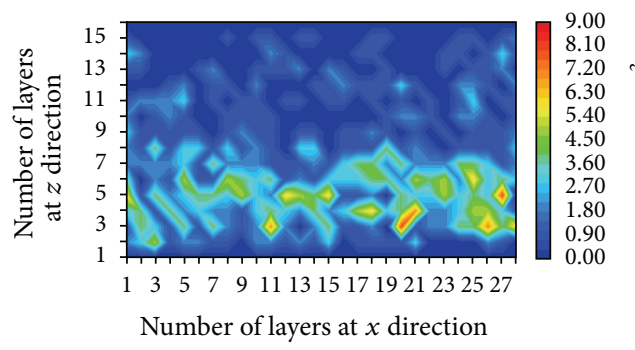

(1)

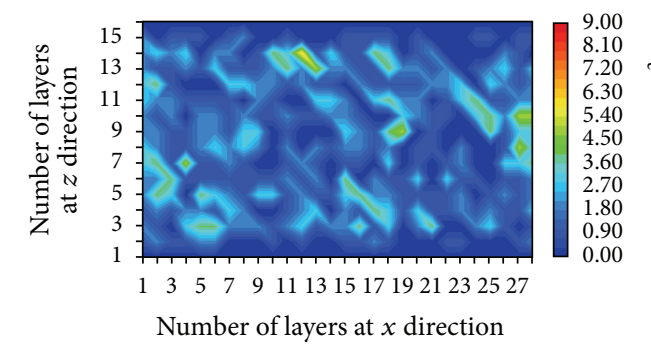

(1)

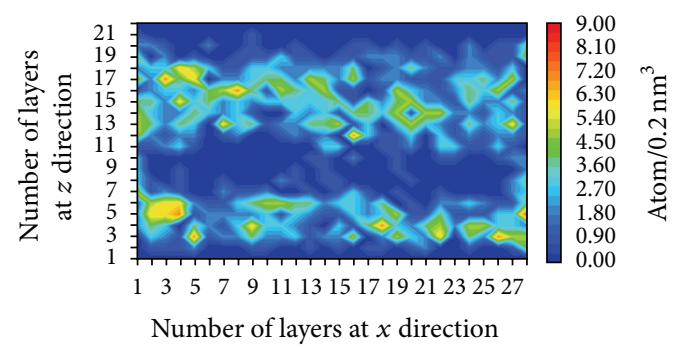

(1)

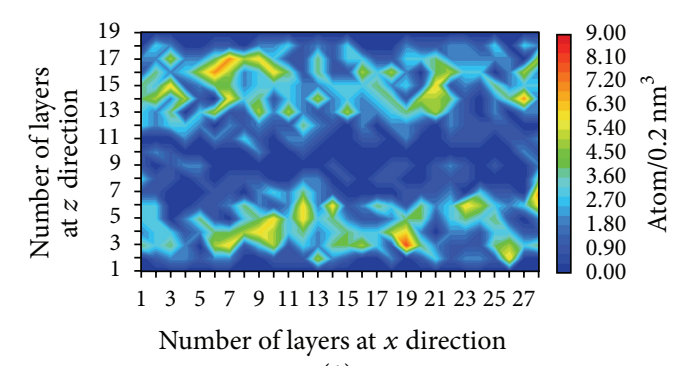

(1)

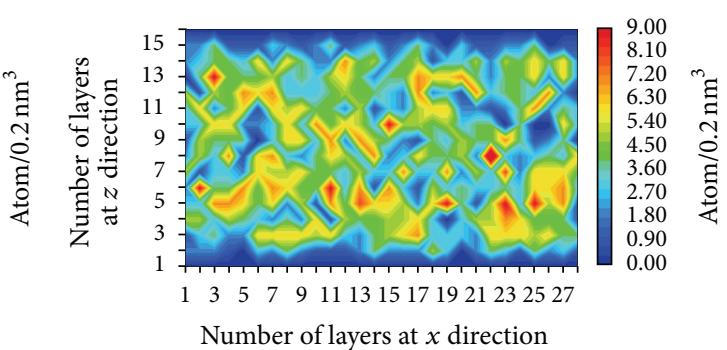

(2)

(a)

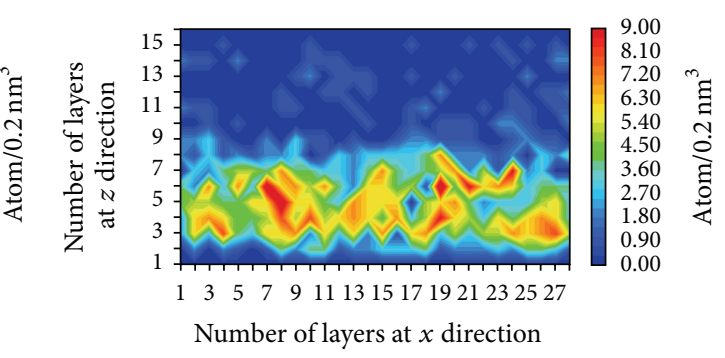

(2)

(b)

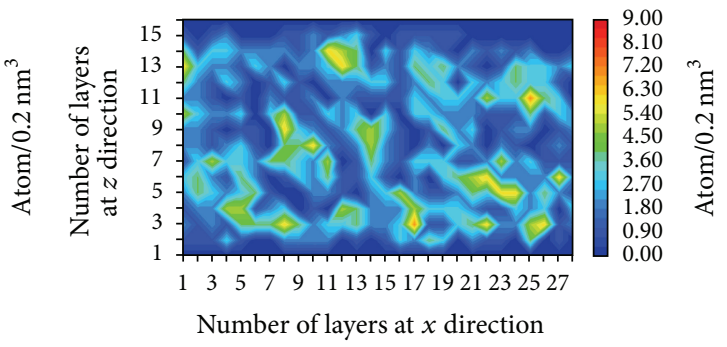

(2)

(c)

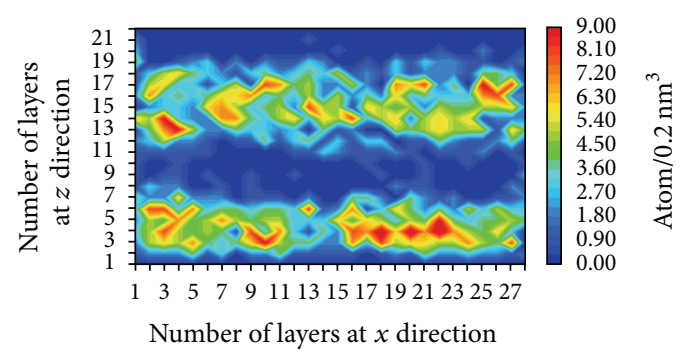

(2)

(d)

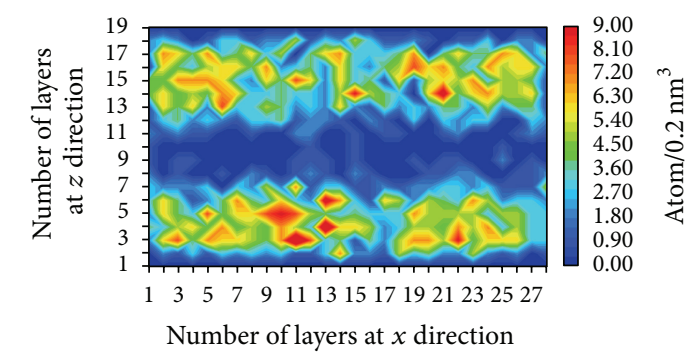

(2)

(e)

FIGURE 3: Distribution of four-coordinate atoms in every specimen in [010] direction ( $x z$ surface). (a) Specimen 1: Si/Ge, (b) Specimen 2: $\mathrm{Si} /(\mathrm{Ge}+\mathrm{Cu}),(\mathrm{c})$ Specimen 3: $(\mathrm{Si}+\mathrm{Cu}) /(\mathrm{Ge}+\mathrm{Cu})$, (d) Specimen 4: $\mathrm{Si} / \mathrm{Cu} / \mathrm{Ge} / \mathrm{Cu}$, and (e) Specimen 5: Si/Cu/Ge. (1) Before annealing and (2) after annealing. 


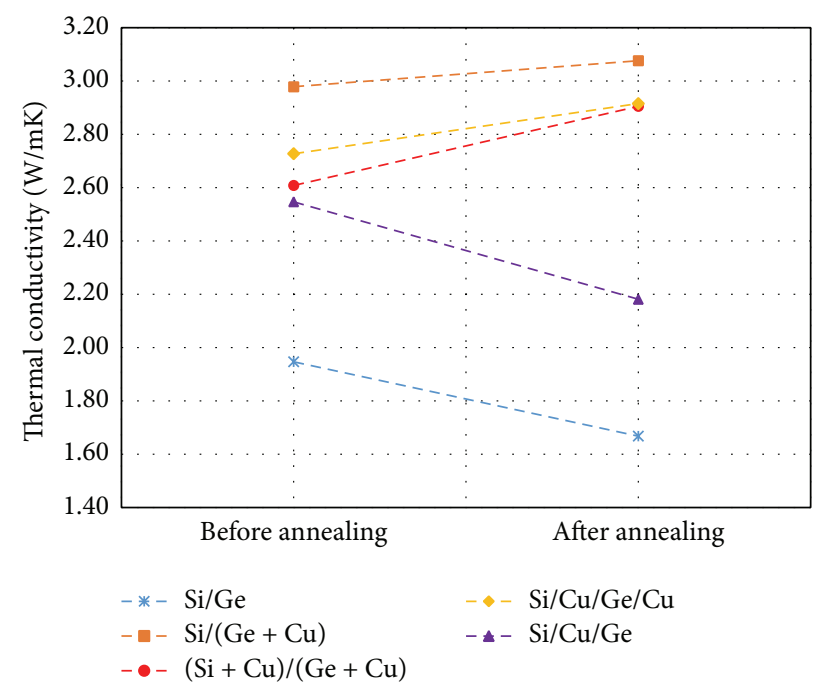

FIGURE 4: Results of thermal conductivity obtained using the GreenKubo equation. Specimen 1: $\mathrm{Si} / \mathrm{Ge}$, Specimen 2: $\mathrm{Si} /(\mathrm{Ge}+\mathrm{Cu})$, Specimen 3: $(\mathrm{Si}+\mathrm{Cu}) /(\mathrm{Ge}+\mathrm{Cu})$, Specimen $4: \mathrm{Si} / \mathrm{Cu} / \mathrm{Ge} / \mathrm{Cu}$, and Specimen 5: $\mathrm{Si} / \mathrm{Cu} / \mathrm{Ge}$.

3.3. Relationship between Cluster Precipitation and Thermal Conductivity. We showed that precipitation of fourcoordinate atoms plays a crucial role in thermal conduction of the studied materials. To understand the relationship between precipitation of four-coordinate atoms and the thermal conductivity, first we summarize the obtained results: (1) All specimens show enhancement of the number of four-coordinate atoms by annealing. (2) Specimen 5 shows the highest enhancement in the number of four-coordinate atoms by annealing, followed by Specimens 1, 4, 2, and 3 . (3) $\mathrm{Cu}$ blocks the precipitation of four-coordinate atoms in the layer where it is doped. (4) $\mathrm{Cu}$ dopant and the thin $\mathrm{Cu}$ layer can enhance precipitation and increase the density of four-coordinate atoms in the $\mathrm{Cu}$-free layers of $\mathrm{Si}$ and $\mathrm{Ge}$. (5) Specimens 1 and 5 show reduction of thermal conductivity by annealing while Specimens 2, 3, and 4 show its increment. (6) $\mathrm{Cu}$ dopant increases the thermal conductivity of these materials.

From these findings, we can make two main considerations. First, increase of the number of four-coordinate atoms during annealing can lower the thermal conductivity. This behavior can be clearly seen in Specimens 1 and 5. Both of these specimens have more four-coordinate atoms and lower thermal conductivity after the annealing. However, Specimens 2, 3, and 4 show the opposite behavior even when the number of four-coordinate atoms increases. This phenomenon leads to the second consideration.

The second consideration is that a high density of fourcoordinate atoms can prevent increment of thermal conductivity and that the densification of the four-coordinate atoms occurs in the $\mathrm{Cu}$-free region in the $\mathrm{Cu}$-added specimens. We can see that $\mathrm{Cu}$ blocked the precipitation of four-coordinate atoms in the layer where it is doped. In Specimen 2, for example, almost no four-coordinate atom can be found in the $(\mathrm{Ge}+\mathrm{Cu})$ layer (compare Figures 3(a) and 3(b)).
However, in the Si layer (the lower region in Figure 3(b)), the number of four-coordinate atoms increases; thus the density of four-coordinate atom increases in that layer. In the $(\mathrm{Ge}+\mathrm{Cu})$ layer, the two contradictory effects on the atomic vibrations exist. $\mathrm{Cu}$ atoms themselves easily transmit the atomic vibrations, whereas the nanoclusters with fourcoordinate atoms may trap them. In contrast, at the $\mathrm{Si}$ layer, the atomic vibrations may only be trapped by fourcoordinate atoms because no $\mathrm{Cu}$ atoms exist in this region. This makes the thermal conductivity of Specimen 2 after annealing change less, while in Specimen 3 the density of four-coordinate atoms after the annealing process increases the least among all the specimens. This leads to a larger increment of thermal conductivity than that of Specimen 2. Moreover, Specimen 3 shows the largest increment compared to all other specimens because the effect of four-coordinate atom is the smallest.

There is an actual experiment conducted by Takiguchi et al. [21], using the $\mathrm{Si} /(\mathrm{Ge}+\mathrm{Au})$ multilayered films. In this study, the crystallization process and control method of the microcrystal size and crystalline fraction were investigated for the specimens with various composition of $\mathrm{Si}, \mathrm{Ge}$, and $\mathrm{Au}$. The result showed that the resistivity of these materials decreased; however, the absolute values of thermoelectric power were $150-200 \mu \mathrm{VK}^{-1}$. This value is almost the same as the conventional thermoelectric power of bulk SiGe. Furthermore, the cluster diameter increased with increasing Au composition and crystalline fraction increased with increasing annealing temperature.

The specimens used in this experiment can be compared with our Specimen 2, Si/( $\mathrm{Ge}+\mathrm{Cu})$. Specimen 2 showed the increment of the number of four-coordinate atoms and the value of thermal conductivity after the annealing process. We can say that these simulation results are consistent with the results obtained by Takiguchi et al. The increment of the number of four-coordinate atoms can correspond to the increment of cluster diameter. Besides, the reason why the value of thermoelectric power of the multilayered $\mathrm{Si} /(\mathrm{Ge}+$ $\mathrm{Au}$ ) systems is almost the same as the bulk $\mathrm{SiGe}$ can be considered. It is the fact that the decrement of the resistivity and the increment of thermal conductivity occur simultaneously by MIC, that is, doping of metallic element and enhancement of crystallization. This phenomenon is confirmed by our simulation, in which the value of thermal conductivity increased when we added $\mathrm{Cu}$ in Specimen 2.

In Specimen 4, two layers of $\mathrm{Cu}$ were added. By adding these layers, precipitation of four-coordinate atom was enhanced in both $\mathrm{Si}$ and Ge layers. Nevertheless, this still cannot prevent the increment of thermal conductivity after annealing because $\mathrm{Cu}$ dopant atoms themselves have a positive effect for increment of thermal conductivity. It should be noted that the $\mathrm{Cu}$ atoms were confined in the form of a thin layer in this specimen and many $\mathrm{Cu}-\mathrm{Cu}$ bonds were formed. However, if we insert just one thin layer of $\mathrm{Cu}$ between the $\mathrm{Si}$ and Ge layers, like Specimen 5 , this decreases the increment of thermal conductivity drastically. As can be seen in Figure 3(e), one thin Cu layer is just enough to enhance the precipitation of four-coordinate atoms. Accordingly the total number of $\mathrm{Cu}$ atoms can be 
reduced to achieve the structure with many four-coordinate atoms. The thermal conductivity is still higher than $\mathrm{Cu}$-free Specimen 1 but it is within a $30 \%$ increase. In addition, doping $\mathrm{Cu}$ in these materials can increase the number of free electrons, thus lowering their electrical resistivity. From the above considerations, we conclude that $\mathrm{Si} / \mathrm{Cu} / \mathrm{Ge}$ is the best structure to improve the conversion efficiency of the $\mathrm{Si} / \mathrm{Ge}$ amorphous multilayer films.

\section{Conclusions}

In this paper, we examined the relationship between the precipitations of four-coordinate atoms and the thermal conductivity of $\mathrm{Si} / \mathrm{Ge}$ amorphous multilayer films by using molecular dynamics simulation. Five specimens were examined: $\mathrm{Si} / \mathrm{Ge}, \mathrm{Si} /(\mathrm{Ge}+\mathrm{Cu}),(\mathrm{Si}+\mathrm{Cu}) /(\mathrm{Ge}+\mathrm{Cu}), \mathrm{Si} / \mathrm{Cu} / \mathrm{Ge} / \mathrm{Cu}$, and $\mathrm{Si} / \mathrm{Cu} / \mathrm{Ge}$. From the analysis of the distribution of fourcoordinate atoms and the thermal conductivity, we clarified the following two competing effects: (1) Increasing the number of four-coordinate atoms by annealing can reduce the thermal conductivity. (2) Cu dopant atoms themselves increase the thermal conductivity of these materials. Combining these two points, we concluded that $\mathrm{Si} / \mathrm{Cu} / \mathrm{Ge}$ is the best structure to improve the conversion efficiency of $\mathrm{Si} / \mathrm{Ge}$ amorphous multilayer films.

\section{Competing Interests}

The authors declare that they have no competing interests.

\section{Acknowledgments}

This work was supported by JSPS KAKENHI Grant no. 26289246.

\section{References}

[1] A. I. Hochbaum, R. Chen, R. D. Delgado et al., "Enhanced thermoelectric performance of rough silicon nanowires," Nature, vol. 451, no. 7175, pp. 163-167, 2008.

[2] D. K. C. M. Donald, Thermoelectricity: An Introduction to the Principles, John Wiley \& Sons, New York, NY, USA, 1962.

[3] D. M. Rowe, Thermoelectrics Handbook: Macro to Nano, CRC Press, Boca Raton, Fla, USA, 2006.

[4] J.-M. Lin, Y.-C. Chen, and C.-P. Lin, "Annealing effect on the thermoelectric properties of $\mathrm{Bi}_{2} \mathrm{Te}_{3}$ thin films prepared by thermal evaporation method," Journal of Nanomaterials, vol. 2013, Article ID 201017, 6 pages, 2013.

[5] X. Kang, M. T. Børset, O. S. Burheim, G. M. Haarberg, Q. Xu, and S. Kjelstrup, "Seebeck coefficients of cells with molten carbonates relevant for the metallurgical industry," Electrochimica Acta, vol. 182, pp. 342-350, 2015.

[6] Z. Ma, X. Wang, and A. Yang, "Influence of temperature on characters of thermoelectric generators based on test bed," Journal of Nanomaterials, vol. 2014, Article ID 719576, 6 pages, 2014.

[7] F. Oki, Y. Ogawa, and Y. Fujiki, "Effect of deposited metals on the crystallization temperature of amorphous germanium film,"
Japanese Journal of Applied Physics, vol. 8, no. 8, pp. 1056-1056, 1969.

[8] H. Takiguchi, A. Matoba, K. Sasaki, Y. Okamoto, H. Miyazaki, and J. Morimoto, "Structural properties of heavily B-doped SiGe thin films for high thermoelectric power," Materials Transactions, vol. 51, no. 5, pp. 878-881, 2010.

[9] B. J. Alder and T. E. Wainwright, "Studies in molecular dynamics. I. General method," The Journal of Chemical Physics, vol. 31, no. 2, pp. 459-466, 1959.

[10] Y. Sasajima, J. Murakami, and A. E. B. M. Tamidi, "Computer simulation of precipitation process in $\mathrm{Si} / \mathrm{Ge}$ amorphous multilayer films: Effects of $\mathrm{Cu}$ addition," Materials Transactions, vol. 54, no. 10, pp. 1905-1909, 2013.

[11] D. Frenkel and B. Smit, Understanding Molecular Simulation, Academic Press, Orlando, Fla, USA, 2001.

[12] D. C. Rapaport, The Art of Molecular Dynamics Simulations, Cambridge University Press, Cambridge, UK, 1995.

[13] J. Tersoff, "New empirical approach for the structure and energy of covalent systems," Physical Review B, vol. 37, no. 12, pp. 69917000, 1988

[14] Z. D. Sha, P. S. Branicio, Q. X. Pei, V. Sorkin, and Y. W. Zhang, "A modified Tersoff potential for pure and hydrogenated diamondlike carbon," Computational Materials Science, vol. 67, pp. 146$150,2013$.

[15] S. Munetoh, T. Motooka, K. Moriguchi, and A. Shintani, "Interatomic potential for $\mathrm{Si}-\mathrm{O}$ systems using Tersoff parameterization," Computational Materials Science, vol. 39, no. 2, pp. 334-339, 2007.

[16] M. B. Kanoun, A. E. Merad, H. Aourag, J. Cibert, and G. Merad, "Molecular-dynamics simulations of structural and thermodynamic properties of ZnTe using a three-body potential," Solid State Sciences, vol. 5, no. 9, pp. 1211-1216, 2003.

[17] T. Nagai, Y. Sasajima, and J. Onuki, "Molecular dynamics simulation of void generation during annealing of copper wiring," Materials Transactions, vol. 50, no. 10, pp. 2373-2377, 2009.

[18] M. S. Green, "Markoff random processes and the statistical mechanics of time-dependent phenomena," The Journal of Chemical Physics, vol. 20, pp. 1281-1295, 1952.

[19] R. Kubo, "Statistical-mechanical theory of irreversible processes. I. General theory and simple applications to magnetic and conduction problems," Journal of the Physical Society of Japan, vol. 12, no. 6, pp. 570-586, 1957.

[20] L. Verlet, "Computer 'experiments' on classical fluids. I. Thermodynamical properties of Lennard-Jones molecules," Physical Review, vol. 159, no. 1, pp. 98-103, 1967.

[21] H. Takiguchi, K. Fukui, and Y. Okamoto, "Annealing temperature dependence of crystallization process of SiGeAu thin film," Japanese Journal of Applied Physics, vol. 49, no. 11, Article ID $115602,2010$. 

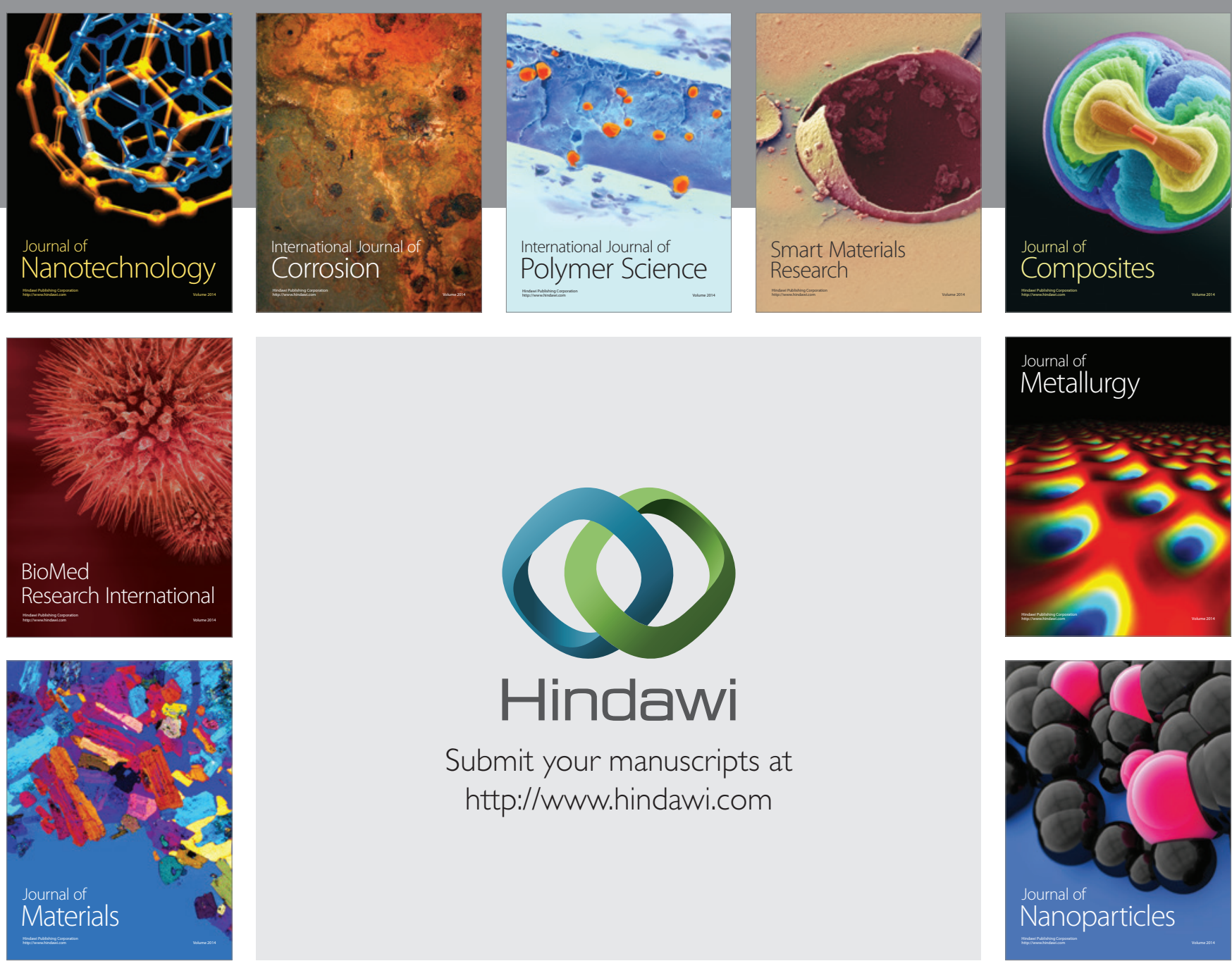

\section{Hindawi}

Submit your manuscripts at

http://www.hindawi.com

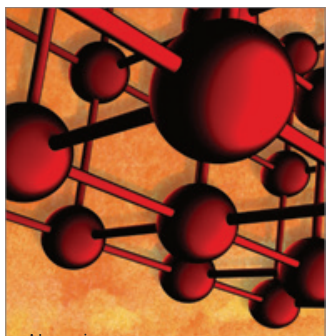

Materials Science and Engineering
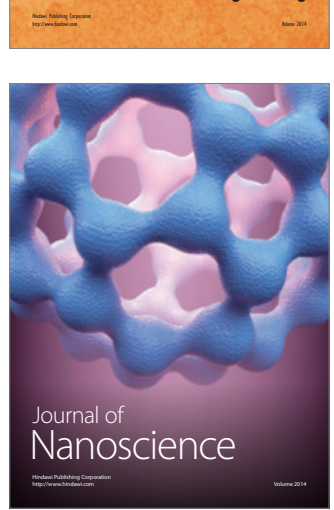
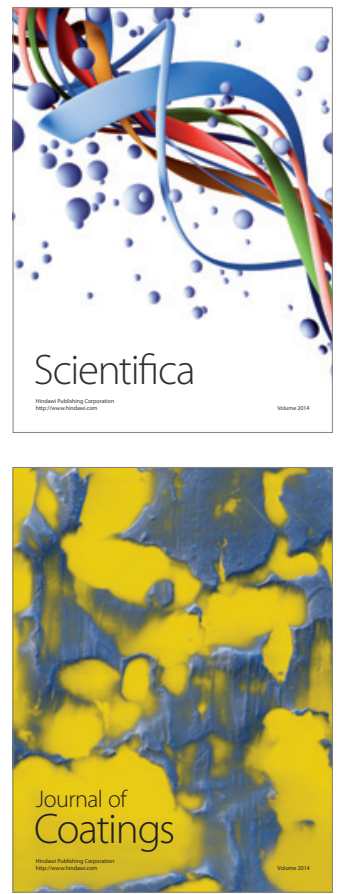
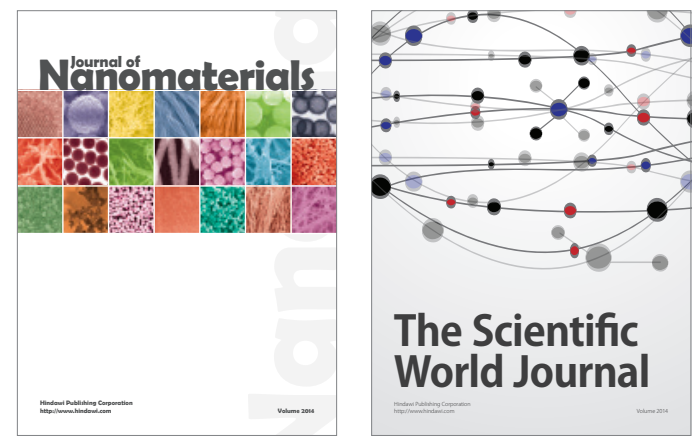

The Scientific World Journal
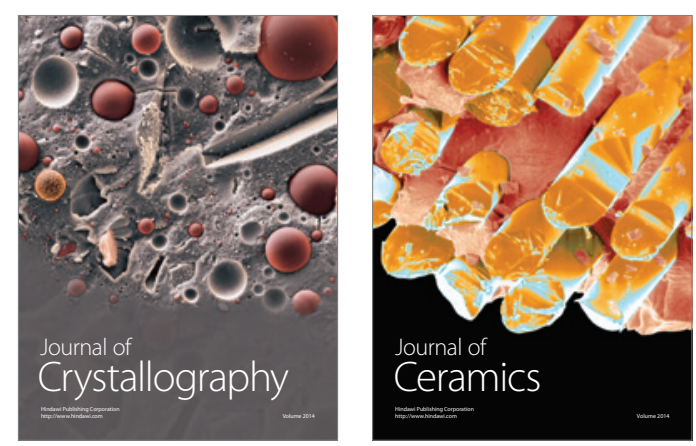
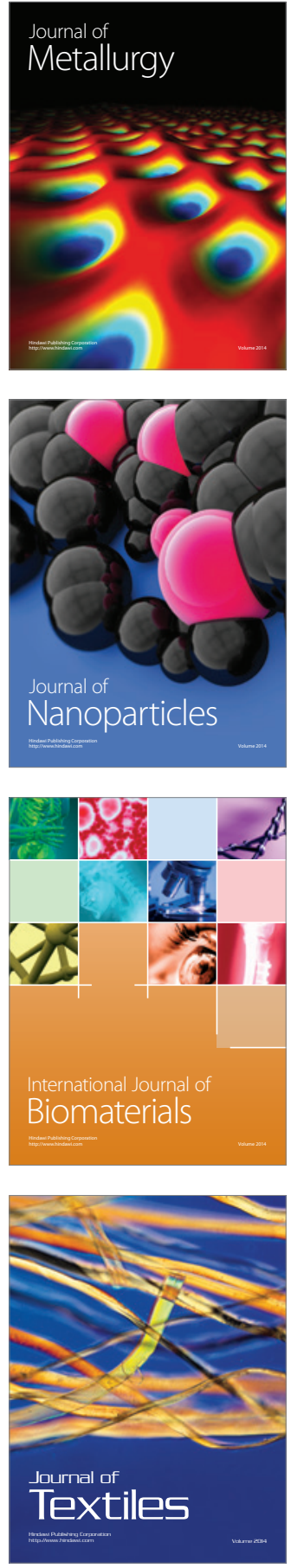